\title{
EDITORIAL \\ Godfrey M Hewitt (1940-2013): highlights in Heredity from a career in evolutionary genetics
}

\author{
Heredity (2013) 110, 405-406; doi:10.1038/hdy.2013.30
}

During his career, Godfrey Hewitt, who died in February of this year, and whose impact on evolutionary biology in Europe has been well documented (Butlin et al., 2006), published a remarkable 44 papers in Heredity. He also directly collaborated with and scientifically influenced the current and previous two Editors-in-Chief of the journal. In this brief article, we pay tribute to his immense scientific contribution by each summarising one of his Heredity papers. In doing so, we aim to highlight not only different aspects of his work and the diversity of his scientific interests, but also his pioneering approach to placing genetic diversity in the context of spatio-temporal processes, integrating an understanding of the ecology, landscape and history of the organisms he studied, and, most importantly, of how these factors interact to provide the myriad of genetic patterns that have been uncovered during the last few decades.

\section{ROGER BUTLIN: SPATIAL DISPERSAL}

For Godfrey, nothing in evolutionary biology made sense except in the light of the ever-changing spatial distributions of organisms. This viewpoint makes the dispersal behaviour of an organism a key part of its natural history, with far-reaching consequences for its ecology and evolution. Early in his career, Godfrey measured grasshopper dispersal (Aikman and Hewitt, 1972) and this influenced his thinking on postglacial colonisation (for example, Hewitt, 1993): a leptokurtic dispersal function is needed to accommodate observations of both rapid colonisation of new habitat and small-scale population structure. Godfrey realised that the significance of a few long-distance dispersers was likely to be much greater when they arrived in empty habitat, for example during range expansion, than when they arrived in occupied habitat. This intuition was tested in an elegantly simple set of simulations published in Heredity and has been now cited more than 400 times (Ibrahim et al., 1996; see Petit, 2011 for a longer review of the impact of this paper).

The key insight was that founding of new demes by long-distance migrants could create a patchy genetic structure that persists for hundreds of generations. This structure was not seen with a normal dispersal function of equal variance. Leptokurtic dispersal also decreased within-deme diversity, owing to the stronger bottleneck effect associated with long-distance colonisation, and this effect also persisted for long periods. These effects can mislead the unwary who attempt to interpret genetic differentiation or isolation-by-distance under equilibrium assumptions, even leading to false implications of divergence under selection. However, Godfrey was more interested in the biological consequences. Chance fixations of alleles during range expansions contribute to the accumulation of divergence and so to the reproductive isolation seen in secondary contact zones. Repeated cycles of expansion and contraction may build complete barriers to gene flow (Hewitt, 1989). The simple realisation that long-distance migrants are critically important during range expansion therefore has substantial implications for hybridisation and speciation.

\section{MIKE BRUFORD: ISLAND BIOGEOGRAPHY}

Although Godfrey's main interests were spatial patterns of genetic structure and their determinants on continental landmasses, he was also fascinated by island biogeography, and his collaboration with Carlos Juan in the mid-1990s brought some interesting insights into speciation processes in the Canary Islands. In two papers, they analysed mitochondrial DNA variation in two species-rich genera of endemic darkling beetles (Pimelia and Hegeter). These analyses were impressive for the time, given the limits of DNA sequencing technology, and the Hegeter study used more than $400 \mathrm{bp}$ of the mitochondrial cytochrome oxidase I gene (now established as the DNA barcoding gene of choice for most animal taxa) for 17 out of the 21 species endemic to the Canaries. Following shortly after Thorpe et al.'s classic 1993, 1994 studies of Canary Island lizards relating phylogeny, colonisation and complex geological history (Thorpe et al., 1993, 1994), Godfrey and Carlos Juan first examined the same questions in the less vagile genus (Pimelia: Juan et al., 1995, 1996). For Pimelia, they had been able to resolve interisland phylogenetic relationships with good statistical support using the same gene but a shorter fragment. However, Hegeter was thought to be a more efficient coloniser than Pimelia, being present on several islands where the latter was absent, so resolution of the colonisation process in Hegeter was anticipated to be more complex.

Indeed, phylogenetic inference for Hegeter taxa did turn out to have lower resolution than in Pimelia, although with supposedly 'intraspecific' variation achieving as much as $12 \%$, we would now infer, using expectations from the many published barcoding studies (for example, Craft et al., 2010), that the samples used are likely to have been harbouring a substantial number of additional, cryptic taxa. However, analysing incipient radiations on a single island was more challenging than establishing among island relationships, due to a lack of statistical support for some of the putatively monophyletic lineages (see below). Nevertheless, the authors were able to establish a plausible colonisation hypothesis and make sensible estimates of the timing of these events.

Radiations on islands were inferred to be much more recent events, with isolation of populations due to volcanic lava flow providing a good candidate mechanism in some cases. However, interestingly, some of the divergence time estimates exceeded the geological ages of the islands themselves. The most sensible explanation for these events was thought to be precolonisation divergence on some of the larger, older islands with the large island ancestors either having gone extinct 
in the intervening period or having gone unnoticed by taxonomists. The Hegeter study was clearly more challenging than the Pimelia one; however, the interpretations of the results were characteristically wellthought-through and added substantially to the body of literature of this region and its interesting evolutionary history. The study has accordingly attracted more than 70 citations and has clearly influenced a large number of subsequent studies on the molecular ecology of island biogeography.

\section{RICHARD NICHOLS: ANALYSIS OF HYBRID ZONES}

Godfrey's last paper published only in February this year (Waters et al., 2013) synthesised the themes of the first two Heredity papers we have chosen: species range expansions across continents and colonisation of islands. In his new paper, he reiterates the fundamental importance of the founding of new populations in unoccupied territory; such events can cause long-lasting genetic differences between populations, which prove resistant to millennia of subsequent gene flow-because of what he called high-density blocking. Thus, evolution cannot be understood without integrating our knowledge of the populations' spatial distribution with our reconstruction of past genetic changes. This insight can be traced back to a key early paper in Heredity (Hewitt, 1975), in which he reports 3 years of work, mapping the geographical course of a hybrid zone between two chromosomal races of the grasshopper Podisma pedestris in the southern French Alps and surrounding mountains. It is remarkable, on rereading it today, to see the germs of the key ideas that subsequently flowered through his academic career. He satisfied himself that the zone was created at the meeting point of two waves of postglacial expansion from different directions, rather than at some boundary between different environments. Why should it not then move or dissipate? He pointed out that a zone maintained by selection against hybrids could move across the landscape, but would become trapped in an area of low population density, because there is net gene flux from either side pinning it in place.

The paper anticipates the experiments that subsequently found evidence for strong selection against hybrids (Barton and Hewitt, 1981a), and further mapping studies showing that the zone appears to be stationary, trapped in the low-density areas just as he had predicted (Barton and Hewitt, 1981b; Nichols and Hewitt, 1986). His careful analysis of the present-day distribution also showed that the course of the zone could not be explained by a single episode of range expansions, but would require expansions and contractions as the climate fluctuated. It was this line of thought that eventually led him to reject the established picture of genetic differentiation becoming established by genetic drift in small populations in glacial refuges, but rather to emphasise the severe drift that will occur at the expanding fronts of a species range as it invades new territory. This and subsequent work took many years of expeditions to the French Alps, and in his papers' acknowledgements to his local hosts, one can detect the warmth of the friendships he built there; he especially enjoyed teasing out, from the older generation, stories about the war and the resistance movements. He relished the natural beauty of this alpine landscape and asked that some of his ashes should find their way there.

\section{CONFLICT OF INTEREST}

The authors declare no conflict of interest.

RA Nichols ${ }^{1}$, RK Butlin ${ }^{2}$ and MW Bruford ${ }^{3}$ ${ }^{1}$ School of Biological and Chemical Sciences, Queen Mary University of London, London, UK; ${ }^{2}$ Department of Animal and Plant Sciences, University of Sheffield, Sheffield, UK and ${ }^{3}$ School of Biosciences, Cardiff University, Cardiff, UK E-mail: BrufordMW@cardiff.ac.uk

Aikman D, Hewitt GM (1972). An experimental investigation of the rate and form of dispersal in grasshoppers. J App/ Ecol 9: 867-877.

Barton NH, Hewitt GM (1981a). The genetic basis of hybrid inviability in the grasshopper Podisma pedestris. Heredity 47: 367-383.

Barton NH, Hewitt GM (1981b). A chromosomal cline in the grasshopper Podisma pedestris. Evolution 35: 1008-1018.

Butlin RK, Rieseberg L, Smith H (2006). Godfrey Hewitt-recipient of the 2005 Molecular Ecology prize. Mol Ecol 15: 301-302.

Craft KJ, Pauls SU, Darrow K, Miller SE, Hebert PDN, Helgen LE et al. (2010). Population genetics of ecological communities with DNA barcodes: an example from New Guinea Lepidoptera. Proc Natl Acad Sci USA 107: 5041-5046.

Hewitt GM (1975). A sex chromosome hybrid zone in the grasshopper Podisma pedestris. Heredity 35: 375-387.

Hewitt GM (1989). The subdivision of species by hybrid zones. In: Otte D, Endler JA (eds.) Speciation and Its Consequences. Sinauer Associates: Sunderland, MA, USA, pp 85-110.

Hewitt GM (1993). Postglacial distribution and species substructure: lessons from pollen, insects and hybrid zones. In: Lees DR, Edwards D (eds) Evolutionary Patterns and Processes. Linnaean Society of London, Academic Press: London, UK, pp 97-123.

Ibrahim KM, Nichols RA, Hewitt GM (1996). Spatial patterns of genetic variation generated by different forms of dispersal during range expansion. Heredity 77 282-291

Juan C, Oromi P, Hewitt GM (1995). Mitochondrial DNA phylogeny and sequentia colonisation of the Canary Islands by darkling beetles of the genus Pimelia (Tenebrionidae). Proc $R$ Soc Lond B 261: 173-180.

Juan C, Oromi P, Hewitt GM (1996). Phylogeny of the genus Hegeter (Tenebrionidae, Coleoptera) and its colonisation of the Canary Islands deduced from cytochrome oxidase I mitochondrial DNA sequences. Heredity 76: 392-403.

Nichols RA, Hewitt GM (1986). Population structure and the shape of a chromosoma cline between two races of Podisma pedestris (Orthoptera: Acrididae). Biol J Linn Soc 29: 301-316.

Petit R (2011). Early insights into the genetic consequences of range expansions. Heredity 106: 203-204.

Thorpe RS, McGregor DP, Cumming AM (1993). Molecular phylogeny of the Canary Island lacertids (Gallotia): mitochondrial DNA restriction fragment divergence in relation to sequence divergence and geological time. J Evol Biol 6: 725-735.

Thorpe RS, McGregor DP, Cumming AM, Jordan WC (1994). DNA evolution and colonisation sequence of island lizards in relation to geological history: mtDNA RFLP, cytochrome b, cytochrome oxidase, 12s rRNA and nuclear RAPD analysis. Evolution 48: 230-240

Waters JM, Fraser $\mathrm{Cl}$, Hewitt GM (2013). Founder takes all: density-dependent processes structure biodiversity. Trends Ecol Evol 28: 78-85. 